\title{
Study on the Alkali Activated Fly Ash Mortar
}

\author{
S. Mandal* and D. Majumdar
}

Civil Engineering Department, Jadavpur University, Kolkata-700032, India

\begin{abstract}
The development of alkali-activated binders seems to present a greener alternative to OPC. The present study has been made on the low calcium fly ash with alkali activator as an alternative binding material as mortar. The mortar has been prepared with ennore sand and Indian fly ash mixed with alkali activator fluid consisting of sodium silicate and sodium hydroxide of different concentrations. The effect of various parameters such as fluid to fly ash ratio, concentration of alkali activators, curing temperature and duration of curing on the compressive strength of mortar at different ages of $3,7,28$ days has been incorporated. 48 hours curing at about $60-70^{\circ} \mathrm{C}$ seems to be optimum for the present alkali activated fly ash mortar.
\end{abstract}

Keywords: Fly ash, Alkali activators, Polymerization, Mortar, Compressive strength.

\section{INTRODUCTION}

It is now well accepted that new binders are needed to replace Ordinary Portland cement (OPC) for enhanced environmental and durability performance. Also the urge to reduce emissions of carbon dioxide (1 tonne of OPC generates almost 1 tonne of $\mathrm{CO}_{2}$ ) and the fact that $\mathrm{OPC}$ structures, which have been built a few decades ago, are already facing disintegration problems points out the handicaps of OPC binders [1]. In fact, the number of premature cases of OPC structures disintegration is overwhelming. Beyond the durability problems originated by imperfect concrete placement and curing operations, the real issue about OPC durability is related to the intrinsic properties of the material. It also presents a higher amount of calcium hydroxide, which reacts with acids generating soluble compounds. On the other hand, the disposing of fly ash, a coal burnt by-product is an environmental issue. As a useful mineral admixture, fly ash has been widely utilised in concrete replacing OPC partially all over the world [2-4].

So far, research works carried out on alkali-activated binders show that this binder is likely to have enormous potential to become an alternative to Portland cement. The present research has been dealt with the activation of Indian fly ash (processed) conforming to Class F as per ASTM) by sodium hydroxide $(\mathrm{NaOH})$ and sodium silicate $\left(\mathrm{Na}_{2} \mathrm{SiO}_{3}\right)$ solution. These two chemicals are commercially available in India. Heat curing is generally needed for fast polymerization of the system to achieve an acceptable strength within a very short period [5-7]. Thus, the mixture may be used as pre-cast products for practical purpose.

This study aims to quantify the effect of the activation chemistry on the compressive strength of mortar. Systematic trials were conducted to optimise the compressive strength

*Address correspondence to this author at the Civil Engineering Department, Jadavpur University, Kolkata-700032, India; Tel: 9133 24169490;

E-mail: mailtosarojmandal@rediffmail.com over a number of parameters. The main focus of this study is to optimize heat curing temperature and curing time to develop an acceptable strength of mortar economically. Based on the present study it has been concluded that heat curing of 48 hours at about $60-70^{\circ} \mathrm{C}$ may be suitable. The other parameters like fluid to fly ash ratio; concentration of activator fluid on the strength of the mortar has been studied. This study may be further modified for development of such concrete mix in future.

\section{EXPERIMENTAL PROGRAM}

\section{Materials}

Processed low calcium fly ash as ULTRACRETE has been used in the study. The main source of the ash is National Thermal Power Corporation, Farakka. The properties of fly ash are described in Table 1. Indian standard sand as per IS 650 [8] was used as fine aggregate. A mixture of $\mathrm{NaOH}$ and $\mathrm{Na}_{2} \mathrm{SiO}_{3}$ was used as alkali activator. The sodium hydroxide used is of commercial grade in pellet forms with $97 \%$ purity and white in colour. Liquid sodium silicate is also a commercial grade having $45 \%$ solid content and specific gravity of $1.53 \mathrm{~g} / \mathrm{cc}$. It is gray in colour and highly viscous. During the preparation of activator liquid of a particular concentration, the effect of impurity in $\mathrm{NaOH}$ and the solid content of $\mathrm{Na}_{2} \mathrm{SiO}_{3}$ have been considered.

\section{Mixture Proportion}

Based on several trials, fifteen numbers of different mortar mixtures have been made as shown in Table 2. Fly ash to fine aggregate ratio was fixed at 1:1 (by weight). Fluid to fly ash ratio (by weight) were $0.45,0.50$ and 0.60 and the concentration of alkali activator fluid was varied as $4 \mathrm{M}, 8 \mathrm{M}$ and $10 \mathrm{M}$. The proportionate amount of $\mathrm{NaOH}$ and $\mathrm{Na}_{2} \mathrm{SiO}_{3}$ were mixed with deionised water to obtain the above concentration. The compositional ratios given in this paper are nominal molar ratios as calculated from the starting chemistry. 
Table 1. Properties of Fly Ash

\begin{tabular}{|c|c|c|}
\hline SI No & Parameter (in Percent) & Results \\
\hline \hline 1 & $\mathrm{SiO}_{2}$ & 91.85 \\
\hline 2 & $\mathrm{Al}_{2} \mathrm{O}_{3}$ & 1.64 \\
\hline 3 & $\mathrm{Fe}_{2} \mathrm{O}_{3}$ & 2.39 \\
\hline 4 & $\mathrm{MgO}$ & 0.14 \\
\hline 5 & ${\mathrm{Sulphur} \mathrm{as} \mathrm{SO}_{3}}$ & 0.09 \\
\hline 6 & Alkalinity & 0.52 \\
\hline 7 & Loss of ignition & 0.76 \\
\hline
\end{tabular}

\section{Mortar Specimens}

Three grades of ennore sand and fly ash were dry mixed. The appropriate amount of activator fluid was added to it and mixed thoroughly by mortar mixer. Mortar cubes of $50 \mathrm{~mm}$ X $50 \mathrm{~mm}$ X $50 \mathrm{~mm}$ size were cast. The mould size of $50 \mathrm{~mm}$ was taken to maintain the better control of the study. The specimens including the mould were kept in an oven for heat curing. The duration of curing was varied as $24 \mathrm{hrs}, 48$ hrs and $72 \mathrm{hrs}$. Curing temperature was fixed at $25^{\circ} \mathrm{C}$ (room temperature), $60^{\circ} \mathrm{C}$ and $90^{\circ} \mathrm{C}$. The curing temperature in the oven is maintained by an automated temperature controller system. Just after curing in the oven, the specimens were demoulded and kept at room temperature till testing. Six mortar cubes were tested for each mixture to get their compressive strength at any age. The strength was measured at 3 days, 7 days and 28 days after casting. The compressive strength was calculated from the applied load at the point of sample failure. The error in the measurement was calculated as the standard deviation of the compressive strength from three samples.

\section{RESULTS AND DISCUSSION}

The fresh mortar mixture was grayish in color and was very cohesive. As expected the mixture become more workable with the increase of fluid to fly ash ratio. Again, with the increase in concentration of activator fluid, the mix becomes less workable due to the less amount of available free water in the mixture. It may also be noted that with the increase in mixing time, the mixture becomes more workable and compactable. The fresh mortar can be easily handled up to 60 - 90 minutes easily and doesn't show any exothermic action at green stage.

Table 3 shows the compressive strength of mortar cubes at different ages cured for 48 hours at $60^{\circ} \mathrm{C}$.It is noted that with the increase in fluid to fly ash ratio, the compressive strength of mortar decreases at all concentration of activator

Table 2. Details of Mixture Proportion

\begin{tabular}{|c|c|c|c|c|c|c|c|c|}
\hline $\begin{array}{c}\text { Mix } \\
\text { Designation }\end{array}$ & $\begin{array}{c}\text { Fly } \\
\text { Ash }(\mathbf{G m})\end{array}$ & \multicolumn{3}{|c|}{ Alkali Activator Fluid ( gm) } & $\begin{array}{c}\text { Fluid to } \\
\text { Flyash Ratio } \\
\text { (by Weight) }\end{array}$ & $\begin{array}{c}\text { Concent } \\
\text {-ration of } \\
\text { Fluid }\end{array}$ & \multicolumn{2}{|c|}{ Types of Temperature Curing } \\
\hline $4 \mathrm{M} 1$ & 1000 & 37.50 & 114.38 & 448.12 & 0.6 & $4 \mathrm{M}$ & 60 & 48 \\
\hline $4 \mathrm{M} 2$ & 1000 & 31.25 & 95.31 & 373.44 & 0.5 & $4 \mathrm{M}$ & 60 & 48 \\
\hline $8 \mathrm{M} 1$ & 1000 & 67.13 & 204.76 & 328.11 & 0.6 & $8 \mathrm{M}$ & 60 & 48 \\
\hline $8 \mathrm{M} 2$ & 1000 & 55.94 & 170.63 & 273.43 & 0.5 & $8 \mathrm{M}$ & 60 & 48 \\
\hline $8 \mathrm{M} 3$ & 1000 & 50.35 & 153.57 & 246.08 & 0.45 & $8 \mathrm{M}$ & 60 & 48 \\
\hline $10 \mathrm{M} 3$ & 1000 & 53.89 & 164.37 & 231.74 & 0.45 & $10 \mathrm{M}$ & 60 & 48 \\
\hline $8 \mathrm{M} 4$ & 1000 & 55.94 & 170.63 & 273.43 & 0.5 & $8 \mathrm{M}$ & \multicolumn{2}{|c|}{ Room temperature } \\
\hline $8 \mathrm{M} 5$ & 1000 & 55.94 & 170.63 & 273.43 & 0.5 & $8 \mathrm{M}$ & 35 & 48 \\
\hline 8M6 & 1000 & 55.94 & 170.63 & 273.43 & 0.5 & $8 \mathrm{M}$ & 90 & 48 \\
\hline $8 \mathrm{M} 7$ & 1000 & 55.94 & 170.63 & 273.43 & 0.5 & $8 \mathrm{M}$ & 60 & 24 \\
\hline $8 \mathrm{M} 8$ & 1000 & 55.94 & 170.63 & 273.43 & 0.5 & $8 \mathrm{M}$ & 60 & 60 \\
\hline $8 \mathrm{M} 9$ & 1000 & 55.94 & 170.63 & 273.43 & 0.5 & $8 \mathrm{M}$ & 60 & 72 \\
\hline
\end{tabular}


fluid of 4,8, and $10 \mathrm{M}$. Unlike normal cement mortar, water in these mixtures remains chemically inactive. Thus the addition of more fluid i.e. water makes the fly ash mortar more porous resulting in the decrease in compressive strength. It is expected that with the increase in concentration of activator fluid the compressive strength of mortar at all ages increases for a particular fluid to fly ash ratio due to higher degree of polymerization activity.

The effect of curing temperature for a particular duration of 48 hours on the compressive strength of mortar has been presented in Fig. (1). As the higher curing temperature accelerates the polymerization reaction, the strength gain seems to be more pronounced at higher curing temperatures.
It is noted that the rate of increase in strength is more up to about $60^{\circ}-70^{\circ} \mathrm{C}$ and after that the strength improvement is not so significant.

Fig. (2) shows the effect of duration of temperature curing on compressive strength at a temperature of $60^{\circ} \mathrm{C}$ which has been fixed based on the present study. Increase in duration of elevated curing temperature increases the compressive strength of mortar. Based on the 28 days strength, 48 hours curing at $60^{\circ} \mathrm{C}$ can achieve about $94 \%$ strength of 72 hours curing at $60^{\circ} \mathrm{C}$.

Therefore, an alternative binding material with Indian fly ash and activator fluid ( a mixture of $\mathrm{NaOH}$ and $\mathrm{Na}_{2} \mathrm{SiO}_{3}$ ) of suitable concentration may be used under heat curing for 48

Table 3. Cube Compressive Strength of Mortar

\begin{tabular}{|c|c|c|c|c|}
\hline \multirow{2}{*}{ Mix. No. } & Fluid to Fly Ash Ratio & \multicolumn{3}{|c|}{ Cube Compressive Strength (MPa) } \\
\cline { 3 - 5 } & & 3 Days & 7 Days & 28 Days \\
\hline \hline $4 \mathrm{M} 1$ & 0.60 & 7.6 & 9.9 & 11.1 \\
\hline $4 \mathrm{M} 2$ & 0.50 & 11.90 & 13.9 & 14.6 \\
\hline $4 \mathrm{M} 3$ & 0.45 & 14.2 & 15.0 & 21.0 \\
\hline $8 \mathrm{M} 1$ & 0.60 & 16.1 & 23.4 & 24.2 \\
\hline $8 \mathrm{M} 2$ & 0.50 & 19.6 & 27.3 & 27.6 \\
\hline $8 \mathrm{M} 3$ & 0.45 & 25.7 & 30.18 & 32.1 \\
\hline $10 \mathrm{M} 1$ & 0.60 & 27.2 & 39.2 & 40.7 \\
\hline $10 \mathrm{M} 2$ & 0.50 & 36.3 & 45.2 & 46.70 \\
\hline $10 \mathrm{M} 3$ & 0.45 & 43.2 & \\
\hline
\end{tabular}

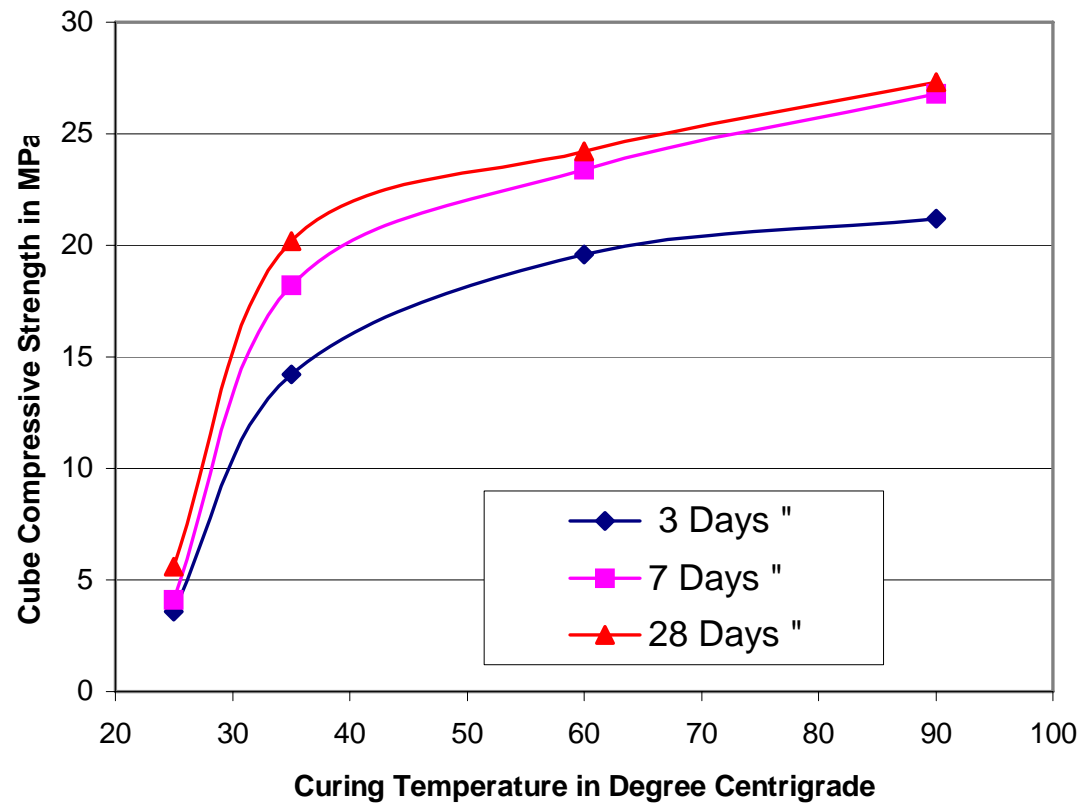

Fig. (1). Effect of curing temperature on alkali activated fly ash mortar. 


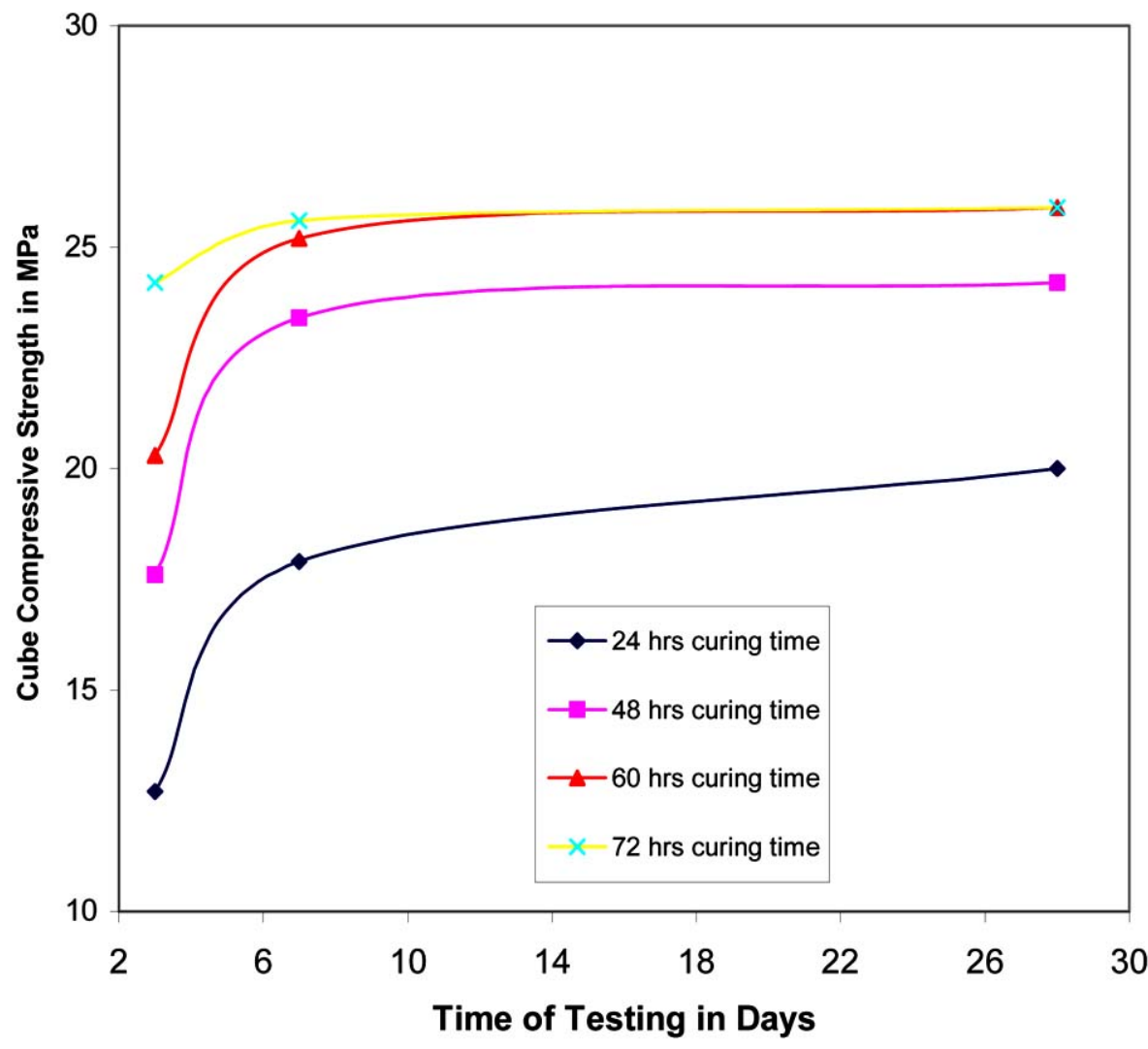

Fig. (2). Effect of curing time at a temperature of $60^{\circ} \mathrm{C}$ on compressive strength of alkali activated fly ash mortar.

hours at a temperature of about $60-65^{\circ} \mathrm{C}$. Such mortar may be used in pre-cast industry. An initiative has been taken up to reduce the amount of heat to achieve an acceptable strength at an early age for all construction purpose.

\section{CONCLUSION}

Based on the present experimental investigation it can be concluded that concentration of activator fluid and the fluid to fly ash ratio has a great effect on the compressive strength. At higher concentration (in terms of molarity) and at low fluid to fly as ratio, the strength of the mortar seems to be maximum. As the curing temperature in the range of $25^{\circ} \mathrm{C}$ to $90^{\circ} \mathrm{C}$ increases, the compressive strength of the mortar also increases. Even strength increases with the longer curing period, however increase in strength beyond 48 years is not significant. Finally, alkali activation of fly ash produces a material with excellent material properties in terms of compressive strength.

\section{ACKNOWLEDGEMENT}

The financial assistance to this experimental study received from All India council of Technical Education, New Delhi, India and their R\&D grant and file no 8023/
BOR/RID/RPS-64/2007-08 dated 24.06.08 is gratefully acknowledged.

\section{REFERENCE}

[1] P.T. Fernando, C.G. Joao, and J. Said, "Alkali-activated binders: A review Part 1. Historical background, terminology, reaction mechanisms and hydration products", Construction Building Material, no. 22, pp. 1305-1314, 2008.

[2] P.K. Meheta, "Durability of concrete: Fifty years of Progress", ACI SP 126, V.M. Malhotra, Ed., 1991, pp. 1-32.

[3] V. M. Malhotra,"High performance high volume fly ash concrete", ACI Concrete International, vol.7, no. 24, pp.1-5, 2002.

[4] R.N. Tarun, "High strength concrete containing large quantities of fly ash", ACI Material Journal, pp. 111-116, 1989.

[5] D. Hardjito, S.E. Wallah, D.M.J. Sumajouw, and V. Rangan, "Fly ash-based geopolymer concrete”, Australian Journal of Structural Engineering, no. 6, pp. 1-9, 2005.

[6] D. Hardjito, and V. Rangan, "Development and properties of lowcalcium fly ash-based geopolymer concrete", Research Report GC, Faculty of Engineering, Curtin University of Technology, Perth, Australia, 2005, pp. 1-130.

[7] R. Matthew, and O.C. Brian, "Chemical optimisation of the compressive strength of luminosilicate geopolymers synthesized by sodium silicate activation of metakaolinite", Journal of Matetial Chem., no. 13, pp.1161-1165, 2003.

[8] IS 650, "Specification for standard sand for testing of cement", Bureau of Indian Standard, 1991.

() Mandal and Majumdar; Licensee Bentham Open.

This is an open access article licensed under the terms of the Creative Commons Attribution Non-Commercial License (http://creativecommons.org/licenses/by-nc/3.0/) which permits unrestricted, non-commercial use, distribution and reproduction in any medium, provided the work is properly cited. 